ISSN: 0213-3563

http://dx.doi.org/10.14201/azafea201921103127

\title{
ESTÉTICA, PELETERÍA Y EXTINCIÓN DE ESPECIES. EL VISÓN EUROPEO COMO EJEMPLO
}

\author{
Aesthetics, fur and species extinction. The European mink as an example
}

\author{
Marta Tafalla González \\ Universidad Autónoma de Barcelona
}

Recibido: 26 de febrero de 2019

Aceptado: 9 de mayo de 2019

\section{RESUMEN}

Una de las principales causas de que el visón europeo, Mustela lutreola, esté en peligro de extinción es la industria peletera. Por un lado, durante los siglos XIX y XX, la caza por su piel causó un grave declive en la especie. Por otro lado, a partir de la década de 1920, la peletería fue substituyendo la caza por la cría en cautividad, y Europa se llenó de granjas de visón americano, Neovison vison; los ejemplares fugados de ellas están colonizando el continente y se han convertido en una amenaza para el visón europeo. Actualmente, algunos países comienzan a prohibir estas granjas, que en cambio aumentan en España. El objetivo de este artículo es analizar este caso concreto como un ejemplo de que nuestros gustos estéticos pueden resultar dañinos e incluso letales para otras especies y la naturaleza en general.

Palabras clave: Visón europeo, Mustela lutreola, visón americano, Neovison vison, estética de la naturaleza, estética animal, belleza natural, ética animal, ética ecológica, peletería.

\section{ABSTRACT}

One of the main causes why the European mink, Mustela lutreola, is in danger of extinction is the fur industry. On the one hand, during the 19th and 20th centuries, hunting for its fur caused a serious decline in the species. On the other hand, from the 1920s the fur industry began to replace the hunt for breeding in captivity, and Europe was filled with American mink, 
Neovison vison, farms; some of them escaped, colonized the continent and have become a threat to the European mink. Nowadays, some countries are beginning to ban these farms, which on the contrary are increasing in Spain. The objective of this article is to analyze this specific case as an example of how our aesthetic tastes may result harmful and even lethal for other species and nature in general.

Key words: European mink, Mustela lutreola, American mink, Neovison vison, environmental aesthetics, animal aesthetics, natural beauty, animal ethics, environmental ethics, fur.

\section{INTRODUCCIÓN}

Uno de los problemas más graves de la catástrofe ecológica que los humanos estamos provocando en la Tierra es el exterminio masivo de especies. Según la IUCN, más de 26.000 especies de animales y plantas están en riesgo de extinción. Una investigación reciente señala que, de todos los mamíferos de la Tierra, solo el $4 \%$ son salvajes, mientras que el $96 \%$ somos humanos y nuestros animales domésticos, especialmente los llamados animales de compañía y los animales criados para trabajar o para comer. De manera similar, solo el $30 \%$ de las aves son salvajes, y el $70 \%$ son aves criadas por la industria ganadera. ${ }^{1}$ Según el "Informe Planeta Vivo" de WWF para 2018, desde los años 70 hemos exterminado el $60 \%$ de los animales salvajes. ${ }^{2}$ Las causas del exterminio son diversas y están interconectadas: destrucción y fragmentación de ecosistemas, sobreexplotación de los recursos, caza, contaminación y cambio climático son las principales. Otra causa fundamental son las llamadas "especies exóticas invasoras", cuya existencia es un efecto secundario de la movilidad humana en un planeta globalizado.

Corresponde a las ciencias el estudio de este exterminio masivo que pone en riesgo la continuidad de la biosfera tal como la conocemos, así como la búsqueda de soluciones. Sin embargo, aquí reivindicamos también una mirada filosófica, que sea capaz de relacionar las causas directas del exterminio de

1. Bar-On, Y. M., Phillips, R., Milo, R., "The biomass distribution on Earth", Proceedings of the National Academy of Sciences of the United States of America, vol. 115, num. 25, (2018), pp. 6506-6511:

https://www.pnas.org/content/115/25/6506

2. Grooten, M., Almond, R.E.A. (eds), "Informe Planeta Vivo - 2018: Apuntando más alto”, WWF, Gland, Suiza, 2018. Traducción al español de Alexandra Walter.

http://awsassets.wwf.es/downloads/informe_planeta_vivo_2018.pdf 
especies con los valores, ideas, costumbres y en general formas de vida propios de nuestra civilización. En este artículo nos proponemos reflexionar sobre el papel que nuestros gustos estéticos pueden llegar a tener en la pérdida de biodiversidad, y para ello vamos a abordar como ejemplo el caso del visón europeo. En los primeros apartados trataremos de exponer de manera sintética la situación de esta especie tan amenazada, para entrar luego en el análisis filosófico de cómo una determinada estética encarnada por la industria peletera sería una de las principales responsables del exterminio de esta especie.

\section{Descripción de la situación ACtUAl del visón EURopeo}

El visón europeo, Mustela lutreola, es un mustélido de pequeño tamaño, que pesa entre 550 y 800 gramos, de cuerpo alargado, patas cortas y con membranas interdigitales en manos y pies. Su aspecto se caracteriza por un precioso pelaje oscuro y brillante, de tono chocolate uniforme, y una mancha blanca en los dos labios. Es un mamífero semiacuático que habita en las riberas de ríos y arroyos en sus tramos medios, donde las aguas transcurren con corriente moderada, así como en lagunas. Necesita una buena calidad del agua y riberas amplias con vegetación densa, pues se oculta entre las raíces de grandes árboles o en la espesura de arbustos, zarzas y carrizales. ${ }^{3}$ Se alimenta de pequeños animales que viven en los ríos o a su alrededor, tales como ratas de agua, ratones, topillos, aves, anfibios, peces, cangrejos e insectos. Es un animal de hábitos nocturnos y crepusculares, solitario y territorial. Machos y hembras tan solo interactúan para reproducirse, y la cría corre a cargo tan solo de la madre. ${ }^{4}$

Hasta el siglo XVIII habitaba gran parte del continente, extendiéndose por centroeuropa hasta los países bálticos y Rusia. Sin embargo, actualmente sufre un grave declive y tan solo sobrevive en unos pocos reductos: Estonia, Bielorrusia y Rusia; el delta del Danubio; el suroeste de Francia y el norte de España. ${ }^{5}$

3. Palomares, F. et. al., "Resting and denning sites of European mink in the northern Iberian Peninsula (Western Europe)", Hystrix, the Italian Journal of Mammalogy, vol. 28, num. 1, (2017), pp. 113-115.

4. Purroy, F. J. y Varela, J. M., Mamíferos de España, Bellaterra, Lynx y SEO/ BirdLife 2016, pp. 62-63. WWF, “Salvemos al visón europeo", Informe de 2017: http:// awsassets.wwf.es/downloads/wwf_vison_europeo_2017.pdf

5. Michaux, J. R., et. al., "Conservation genetics and population history of the threatened European mink Mustela lutreola, with an emphasis on the west European population”, Molecular Ecology, vol. 14, (2005), pp. 2373-2388. 
El pequeño reducto español se extiende por las cuencas cantábricas (Norte de Navarra, País Vasco y noreste de Burgos) y el valle del Ebro (centro y sur de Navarra, Álava, La Rioja, Zaragoza y norte de Burgos y Soria). Sus mayores densidades se hallan en los afluentes del Ebro. ${ }^{6}$ En 2003 se estimó que debía haber unos 500 ejemplares adultos en España. ${ }^{7}$ La Unión Internacional para la Conservación de la Naturaleza la clasificó en 2011 en la Lista Roja de Especies Amenazadas como «en peligro crítico de extinción”, que es la máxima categoría de amenaza. Podría extinguirse en menos de 10 años.

Esta especie está en grave declive debido a una serie de causas que se retroalimentan entre sí. ${ }^{8}$ Una de ellas es la destrucción, fragmentación y degradación de los ecosistemas de ribera. Nuestra civilización tiende a gestionar el agua de los ríos como si fuera de uso exclusivo humano y por ello canaliza los cursos de agua para convertirlos en meras tuberías, emplea cantidades excesivas sin respetar el caudal ecológico, construye embalses y centrales hidroeléctricas. A menudo ocupa las orillas de los ríos con prácticas agrícolas y ganaderas, o construyendo ciudades o fábricas, de modo que destruye la vegetación de ribera y elimina el hábitat de los visones. Asimismo, la contaminación creciente del agua con todo tipo de productos tóxicos les afecta también gravemente. Y aún hay que añadir los atropellos, que son un problema creciente para muchos mamíferos terrestres, así como también para diversos anfibios y reptiles.

Y finalmente, hay dos causas íntimamente relacionadas. A finales del siglo XIX y principios del XX, la caza intensiva de la especie para comercializar su piel provocó un declive importante, en especial en Finlandia y Rusia.

6. http://lifelutreolaspain.com/el-vison-europeo/habitat

7. Gómez, A. y Põdra, M. (2016). "Seguimiento de la aplicación de la estrategia para la conservación del visón europeo”. Documento inédito para el Grupo de Trabajo de Visón Europeo.

8. Maran, T. y Henttonen, H., "Why is the European mink (Mustela lutreola) disappearing? -A review of the process and hypotheses", Ann. Zool. Fennici, vol. 32, (1995), pp. 47-54.

LodÉ, T., et. al., "Decline in Endangered Species as an Indication of Anthropic Pressures: The Case of European Mink Mustela lutreola Western Population”, Environmental Management, vol. 28, num. 6, (2001), pp. 727-735.

Palazón, S., et. al., "Causes and patterns of human-induced mortality in the Critically Endangered European mink Mustela lutreola in Spain”, Oryx, vol. 46, num. 4, (2012), pp. 614-616.

Põdra, M. y Gómez, A., "Rapid expansion of the American mink poses a serious threat to the European mink in Spain”, Mammalia, vol. 82, num. 6, (2018), pp. 580-588. 
Posteriormente, a partir de 1920, a medida que la industria peletera comenzó a substituir la caza por la cría en cautividad, por toda Europa proliferaron las granjas de peletería, que criaban visón americano. En cuanto se establecieron las granjas, algunos ejemplares lograron escapar de ellas. En España, los primeros informes de individuos viviendo en el medio natural son de los años 70.

El visón americano, Neovison vison, es un animal de mayor tamaño, que puede llegar a pesar 1500 gramos. Su pelaje es más oscuro, aunque en algunas granjas se seleccionan artificialmente tonos más grises; y mientras que el europeo tiene una mancha blanca en ambos labios, el americano presenta una mancha blanca en el labio inferior, nunca en el superior. El visón americano compite con el europeo por el mismo hábitat y la misma dieta, pero es de mayor tamaño, más agresivo y se adapta mejor, siendo capaz de vivir incluso en tramos urbanos de los ríos y en aguas en peor estado. Sus camadas son más numerosas. Además, a veces ataca directamente al visón europeo, sobre el que actúa como un depredador. En consecuencia, esta especie exótica introducida por la industria peletera, se ha ido convirtiendo en una amenaza para la supervivencia del visón europeo. Se ha expandido por una veintena de países, y en España ha colonizado una cuarta parte del territorio, de manera que su área de distribución es ya mucho mayor que la del visón europeo: Galicia, Madrid, Castilla y León, Cantabria, País Vasco, Aragón, Cataluña, Valencia. El visón americano también afecta a otras especies autóctonas: a mustélidos como el turón, a mamíferos semiacuáticos como el desmán ibérico y la rata de agua, y a algunas especies de anfibios.

Así, la peletería es doblemente culpable del declive del visón europeo, primero por la caza de esta especie hasta reducir gravemente el número de inviduos, y luego por la cría en cautividad del visón americano, que al escapar se ha convertido en un competidor.

\section{Trabajando por salvar al visón europeo}

Dado el grave riesgo de extinción de la especie, el pequeño reducto que queda en España es muy valioso. Por ello, desde hace décadas, diversas instituciones trabajan con urgencia en su protección. Vamos a repasar algunas de las principales actuaciones que se están llevando a cabo en la actualidad, sin pretender ser completamente exhaustivos debido a la brevedad de este artículo. 
Life+ Territorio Visón es un proyecto financiado por la Unión Europea, el Gobierno de Navarra y el Ministerio de Medio Ambiente, Medio Rural y Marino que tuvo lugar entre 2010 y 2018. Se dedicó a recuperar hábitats fluviales de Navarra que son muy valiosos para el visón europeo: el curso bajo de los ríos Aragón y Arga, dos afluentes del Ebro, incluidos en la Red Natura 2000..$^{9}$ El proyecto anunciaba su programa de trabajo en la web: "Se llevarán a cabo proyectos de restauración de las llanuras de inundación naturales [de los ríos], hoy en día ocupadas por la agricultura y las plantaciones forestales. Se prevé la compra de tierras privadas y arrendamientos de los derechos de uso de tierras públicas, para compensar la pérdida de beneficios derivados del abandono de las actividades desarrolladas en las llanuras aluviales que se van a restaurar. Una vez alcanzados los acuerdos con los propietarios privados y los municipios, se llevarán a cabo la retirada de escolleras y las obras de restauración del hábitat. Especial cuidado se tendrá en el uso de especies vegetales autóctonas y sus variedades. Esto se garantiza mediante la producción en viveros que producirán el material vegetal necesario, a partir de semillas recolectadas en el lugar. También se eliminarán las especies invasoras que reducen la diversidad biológica y son perjudiciales para la conservación de las especies autóctonas."10

Algunos tramos de los ríos habían sido modificados para que transcurrieran más rectos y se habían canalizado parcialmente o protegido con esculleras, lo que había alterado su comportamiento y la relación con el entorno. Este proyecto se dedicó a retirar elementos humanos que encauzaban y modificaban los cursos fluviales, y a reconectar los meandros que habían sido abandonados, permitiendo así que los ríos recuperaran su dinámica natural. En algunos lugares, además, se habían creado canales de regadío encauzados con hormigón, que son una trampa para los animales como el visón, que una vez dentro no pueden volver a salir, por lo que se colocaron rampas de salida. Las actuaciones han ido acompañadas de un programa de comunicación dirigido a distintos sectores sociales, a los que se ha ofrecido participar en el proyecto, dedicando especial atención a las escuelas de la zona.

Este proyecto no es solo enormemente útil en un sentido práctico, sino que podríamos considerar que incluye una perspectiva filosófica, por como nos invita a cambiar nuestra concepción de los ríos. La civilización industrial capitalista basada en el dominio y la explotación de la naturaleza ha tendido

9. "Life+ Territorio Visón", suplemento del num. 358 de la revista Quercus, diciembre de 2015.

10. https://www.territoriovison.eu/index.php/es/life-vison/areas-de-actuacion 
a modificar los cursos de los ríos y encauzarlos, lo que ha resultado dañino para los ecosistemas y las especies que los habitan. Este proyecto ha puesto en práctica medidas de restauración de los ríos y los ecosistemas de ribera que consisten en dejar que la naturaleza fluya con mayor libertad. Lo que han hecho es liberar los ríos de las estructuras artificiales que los confinaban y dirigían, y dejar que puedan desarrollarse a dinámica natural. Estas prácticas se defienden desde la ética ecológica con los conceptos de rewilding y renaturalization, que podrían traducirse como resilvestrar y renaturalizar. La propuesta del rewilding consiste en renunciar al dominio de la naturaleza, ayudarle a recuperarse del daño que le causamos (reintroduciendo especies en declive y retirando infraestructuras que obstaculizan los ciclos y flujos naturales) y permitirle fluir libremente. ${ }^{11}$

Otro proyecto fundamental es Life Lutreola Spain, financiado por la Unión Europea, y en el que colaboran distintos municipios, diputaciones y comunidades autónomas, que se desarrolla entre 2014 y 2019 en el País Vasco, La Rioja, Aragón y Comunidad Valenciana. Este proyecto se propone tres objetivos generales: “(a) eliminar los núcleos de visón americano dentro del área de distribución y zonas de riesgo del visón europeo, (b) aumentar la viabilidad de la población salvaje de visón europeo mediante el refuerzo poblacional y la creación de nuevos núcleos, (c) crear una red de seguimiento para evaluar la situación de ambas especies de visones.”12

Para lograr el segundo objetivo, este proyecto contribuye a la cría en cautividad, y entre 2017 y 2018 ha liberado 34 ejemplares. ${ }^{13}$ Para mejorar sus posibilidades de supervivencia en el medio natural, se ha estudiado con detenimiento los mejores lugares donde liberarlos y también distintos tipos de liberación. Una de las fórmulas que parece ser más exitosa es que los visones, antes de ser liberados, pasen un tiempo en "jaulones presuelta”, unos espacios cerrados que imitan su hábitat, donde viven en condiciones de semilibertad y pueden entrenar sus habilidades de manera segura. En ellos se intenta

11. Véase una síntesis en Monвiot, G., Feral. Rewilding the Land, the Sea and Human Life, Chicago, The University of Chicago Press 2014. Traducción: Salvaje. Renaturalizar la tierra, el mar y la vida humana, Madrid, Capitán Swing, 2017, traducción de Momplet Chico, A.

12. http://lifelutreolaspain.com/proyecto-life-lutreola-spain/objetivos

13. Véase, por ejemplo: http://lifelutreolaspain.com/noticias/suelta-exitosa-de-lenito

Gómez, A.,"Cuatro años del proyecto Life lutreola spain”, ponencia dentro del seminario final del proyecto en noviembre de 2018: https://www.youtube.com/ watch?v=e6kxUBJx4iw 
reducir al mínimo el contacto con los humanos. ${ }^{14}$ Muchos de los ejemplares que se sueltan van radiomarcados, y se hace un seguimiento para comprobar su adaptación. Además, dado que la población española es muy pequeña y tiene una baja diversidad genética, se está realizando cría experimental cruzando ejemplares de la población española con ejemplares de Estonia. ${ }^{15}$

El proyecto incluye otras acciones, como analizar el problema de los atropellos y proponer medidas correctoras, y también adquirir algunos terrenos en el río Ebro para acondicionarlos como hábitat para el visón. Asimismo trabaja dando a conocer la especie y sensibilizando a la sociedad sobre su riesgo de extinción. Desde este proyecto son conscientes de que la sociedad española no considera al visón europeo una especie emblemática, a diferencia por ejemplo del lince ibérico, lo que resulta un problema añadido para su conservación. Por ello han desarrollado materiales y actividades de divulgación, especialmente destinados a escuelas. ${ }^{16}$

Por otra parte, WWF ha diseñado y propuesto al Ministerio y las Comunidades Autónomas un Plan de Emergencia con una duración de tres años (2017-2020) que implica tres medidas principales. ${ }^{17}$ La primera consiste en realizar un censo nacional del visón europeo, que debería elaborarse de manera coordinada entre las distintas comunidades autónomas, unificando criterios y metodologías, y con la colaboración del proyecto Life Lutreola Spain, para conocer de manera precisa la situación de la especie.

La segunda es evitar la expansión del visón americano, lo que incluye dos líneas de trabajo. Por un lado hay una vía de prevención: “evitar/limitar la creación de nuevas granjas peleteras y mejorar la regulación de las existentes, ya que no cuentan con las medidas de seguridad suficientes y todavía suponen un riesgo para la biodiversidad". ${ }^{18}$ Y por otro lado es necesario el control de los ejemplares que ya están en el medio natural, y esto exige "una aplicación efectiva de la Estrategia de gestión, control y erradicación del visón americano,

14. http://lifelutreolaspain.com/content/construccion-de-jaulones-presuelta

15. Maran, T., "Perspectivas de la conservación ex situ del visón europeo en Europa”, ponencia dentro del seminario final del proyecto en noviembre de 2018: https:// www.youtube.com/watch? $\mathrm{v}=03-9 \mathrm{P} 7 \mathrm{vLd}-\mathrm{g} \& \mathrm{t}=412 \mathrm{~s}$

16. Véase, por ejemplo, el cuaderno con actividades educativas: http://lifelutreolaspain.com/sites/default/files/recursos-didacticos/cuaderno_castellano_9pag.pdf

17. WWF, "Propuesta de medidas para el desarrollo de un Plan de Emergencia para evitar la extinción del Visón europeo en España”, 2017:

http://awsassets.wwf.es/downloads/Propuesta_de_Plan_de_Emergencia_WWF_Julio_2017.pdf

18. https://www.wwf.es/nuestro_trabajo_/especies_y_habitats/vison_europeo_/ 


$$
\begin{gathered}
\text { MARTA TAFALLA GONZÁLEZ } \\
\text { ESTÉTICA, PELETERÍA Y EXTINCIÓN DE ESPECIES. } \\
\text { EL VISÓN EUROPEO COMO EJEMPLO }
\end{gathered}
$$

para controlar la expansión de las poblaciones asilvestradas de esta especie invasora."

La tercera medida es reforzar el programa de cría en cautividad con el fin de la reintroducción. Desde 2008, existe un Programa de Conservación Ex Situ del Visón Europeo en España, y sin embargo, no está funcionando como debería. Se requiere una inversión económica continuada para darle un fuerte impulso. También en este caso se colaborará con el proyecto Life Lutreola Spain.

Además, WWF también pide medidas de restauración de los ríos, retirar elementos artificiales que ya no se usan pero siguen actuando como barreras, y reforzar la conectividad de las cuencas fluviales donde habita la especie. Y asimismo está desarrollando un plan de concienciación social acerca de la importancia y la situación de peligro del visón europeo.

Por su parte, el Gobierno de Navarra ha instalado pasos de fauna en las carreteras donde se habían detectado más atropellos, y ha comprobado que no solo los usan los visones, sino también otros animales.

Y finalmente, el Ministerio para la Transición Ecológica ha declarado el visón europeo "especie en situación crítica”. Esta declaración, consensuada con las Comunidades Autónomas afectadas, se publicó en el BOE con fecha de 17 de octubre de 2018, y permite al gobierno declarar de interés general los proyectos que se emprendan para recuperarlo y tramitarlos de manera urgente. ${ }^{19}$

Hay que agradecer a todas estas instituciones, y a cada una de las personas implicadas, los enormes esfuerzos que dedican a salvar esta especie en una situación de máxima urgencia. El trabajo que realizan requiere tesón y perseverancia, y desgraciadamente es una tarea poco reconocida por la sociedad. Deberíamos ser conscientes de lo que significa este ingente trabajo: no solo está evitando la extinción de una especie, sino que contribuye a proteger los ecosistemas de ribera y la biodiversidad que los habita. Además, conviene resaltar una cuestión: la diversidad de las actuaciones necesarias para salvar al visón europeo permite comprender los muchos factores implicados en la extinción de una especie. Necesitamos esa mirada panorámica que muestra cómo la forma en que los humanos habitamos un territorio puede afectar a las otras especies de maneras diversas. Todo ello debería enseñarnos a ser más prudentes en nuestra relación con la naturaleza.

19. https://www.boe.es/boe/dias/2018/10/17/pdfs/BOE-A-2018-14181.pdf. 
Para mostrar la complejidad de esta problemática, merece la pena prestar atención a un elemento que invita a un cierto debate ético: la erradicación del visón americano. Dado que esta especie exótica invasora se ha convertido en una de las principales amenazas para la supervivencia del visón europeo, las instituciones implicadas en salvar al visón europeo colaboran en el descaste del visón americano. En 2014, el Ministerio de Agricultura, Alimentación y Medio Ambiente publicó la "Estrategia de gestión, control y erradicación del visón americano en España”, donde se detallan los daños que causa esta especie, y se diseña un programa para su eliminación..$^{20} \mathrm{La}$ cuestión no es baladí, porque implica matar individuos de una especie para salvar a los individuos de otra.

\section{El debate acerca del visón Americano}

Veamos en primer lugar cómo se lleva a cabo esta erradicación. El control del visón americano se realiza mediante trampeo selectivo. El método que se ha comprobado más eficaz, después de probar otros sistemas con anterioridad, es el siguiente: se han diseñado unas plataformas flotantes con un túnel de madera que se colocan en los ríos. En su interior hay un "huellero", una bandeja con una mezcla de arcilla y arena donde los animales que entren dejarán sus huellas, lo que permitirá comprobar si un visón americano está visitando la plataforma. Cuando se detecta que los visones americanos están entrando a curiosear, se instala una jaula que permite atraparlos. Los ejemplares capturados son matados. Life Lutreola Spain trabaja con este protocolo:

"Los visones americanos capturados, se sacrificarán mediante los siguientes métodos:

1. Agentes farmacéuticos inyectables: Por ejemplo, sacrificio con previa anestesia con una inyección intramuscular de ketamina (Imalgene 1000/500 (C) en combinación con xylacina (Rompun () o medetomidina (Domtor (C). Aplicada bajo la supervisión de un veterinario.

2. Agentes inhalables: $\mathrm{CO}_{2}$. Sistemas de asfixia con $\mathrm{CO}_{2}$. Los ejemplares se trasladan a las instalaciones donde se encuentran estos dispositivos y son introducidos en cámaras estancas.

20 https://www.miteco.gob.es/es/biodiversidad/publicaciones/pbl_exo_inva_vison_americano_tcm30-69978.pdf. 
3. Métodos físicos: Disparos mediante arma de aire comprimido. No es necesaria licencia de armas ni inmovilización del ejemplar. Se realiza in situ en el lugar de la captura y en la misma trampa. Es el método principal empleado para el sacrificio de los visones americanos capturados en el Reino Unido (Reynolds et al 2004). El sacrificio de los visones americanos in situ reduce el estrés de los ejemplares, costes, y esfuerzos de traslado y manejo." 21

El programa de descaste del visón americano para salvar al visón europeo invita a un debate ético que resulta paradigmático de las divergencias entre ecologistas y animalistas. En realidad no está teniendo lugar un debate muy sonoro ni intenso, dado que la situación de ambas especies parece despertar poco interés en la opinión pública, en comparación con otras problemáticas. Pero sí hay un cierto debate, aunque sea muy modesto, y merece la pena analizarlo por su interés filosófico. Mientras que los ecologistas ven con claridad que es necesario erradicar a la especie exótica invasora para salvar a la especie autóctona, los animalistas denuncian que esta perspectiva solo reconoce valor moral a las especies y no a los individuos, lo que consideran un error. Los animalistas argumentan que quienes realmente sienten y sufren son los individuos, no las especies, y por ello son quienes necesitan mayor protección..$^{22}$ Mientras los ecologistas afirman que la defensa de la naturaleza debe centrarse en especies y ecosistemas, esto es, en sujetos colectivos, los animalistas sostienen que la prioridad es proteger a los individuos. Esta diferencia se presenta a veces como una oposición irreconciliable. Yo creo, en cambio, que ambas perspectivas son complementarias y se necesitan mutuamente para entender y defender la naturaleza, y por ello considero necesaria la cooperación entre ecologistas y animalistas.

Es cierto que en algunos casos, como éste, sus posiciones parecen de entrada irreconciliables. Aquí, la divergencia aumenta porque algunos ecologistas denuncian que fueron precisamente activistas animalistas contrarios a la explotación de animales por la industria peletera quienes liberaron algunos

21. Life Lutreola Spain, "Protocolo de erradicación de visón americano", Abril de 2017, p. 19.

http://lifelutreolaspain.com/sites/default/files/documentos/a.3_protocolo_erradicacion_va_v3_life13nates1171.pdf

22. http://www.igualdadanimal.org/noticias/6346/protestamos-por-la-matanzade-animales-denominados-invasores

https://pacma.es/el-gobierno-permitira-el-exterminio-de-millones-de-animales/ 
visones americanos de las granjas. Ante dicha acusación, es necesario dejar claro que no forma parte de la estrategia del movimiento animalista español liberar animales que están siendo explotados, ya sea en la industria peletera, cárnica, láctea o de experimentación. La inmensa mayoría de los textos de ética animal que se publican en España, así como la inmensa mayoría de las asociaciones animalistas activas en el Estado, no defienden la liberación de animales explotados, porque son conscientes de que liberar a algunos individuos no resuelve el problema de fondo, y asimismo saben que en algunos casos puede incluso generar problemas nuevos y difíciles de resolver.

Ante las injusticias cometidas contra los animales, las organizaciones animalistas españolas suelen optar por las siguientes estrategias: fotografiar y grabar la situación de los animales explotados y difundirla en medios de comunicación y redes sociales; elaborar documentales y publicaciones de denuncia; intentar que se respeten al máximo las leyes de protección animal y poner denuncias en los juzgados cuando no se respetan; intentar mejorar las leyes de protección animal mediante lobby político; concienciar a la sociedad para que deje de comprar productos basados en la explotación animal; introducir la ética animal en todos los niveles educativos, desde primaria hasta la universidad; organizar manifestaciones y campañas de protesta. ${ }^{23}$ Así pues, no puede acusarse al movimiento animalista español de promover las sueltas de visones americanos. Si realmente hubo alguna persona que soltó a algunos ejemplares, lo hizo a título individual, no amparada en la manera de trabajar del movimiento animalista español, y probablemente desconociendo las consecuencias de sus actos. Obviamente, no se puede solucionar una injusticia generando otra. Soltar visones americanos de las granjas peleteras españolas es un error con terribles consecuencias para otras especies.

En realidad, la causa principal de que algunos visones hayan escapado de las granjas no han sido liberaciones intencionadas. El periodista especializado en temas medioambientales Raúl Rejón explica: "Las acciones de grupos animalistas que han soltado miles de ejemplares se han convertido en una imagen común a la hora de explicar la proliferación de esta especie en los cursos de agua. Sin embargo, el origen del problema es bien distinto. En Galicia, la colonización comenzó con fugas en diversas granjas del sureste en los años 60 del siglo XX. En Cataluña se constató que las primeras poblaciones surgieron por los escapes en una granja comercial en Viladrau

23. Véase, por ejemplo, los objetivos y campañas del Partido animalista PACMA, o de ONG como ADDA, AnimaNaturalis, AVATMA, FAADA, Igualdad Animal, Libera!, Fundación Franz Weber. 
y otra en Taradell, tras un incendio forestal en 1983. En Aragón, los visones comenzaron a medrar en 1990 al abandonarse una explotación en Teruel con 8.000 ejemplares. El informe técnico explica que "a pesar de la alta mortandad por inanición y canibalismo" en un año habían colonizado los ríos." ${ }^{24}$

Volvamos ahora al debate sobre el exterminio del visón americano. Para entenderlo, conviene prestar atención a lo siguiente. La situación en la que se encuentra el visón europeo es muy injusta, por supuesto, pero la situación también es injusta para el visón americano. Fijémonos simplemente en los discursos que articulamos sobre esta problemática: tendemos a culpabilizar al visón americano de la extinción del visón europeo, lo denominamos "invasor" y con ello justificamos que los ejemplares de esta especie que se hallen en España deben ser eliminados. Pero ese discurso no deja de ser tramposo, porque el visón americano no vino a España por decisión propia, sino a causa de los negocios humanos: debido a la existencia de una industria que cría animales en condiciones brutales y crueles para vender sus pieles, debido a los diseñadores que confeccionan prendas de piel, debido a un sector de la moda que promociona esos productos, debido a las tiendas que los comercializan y debido a los consumidores que pagan por ellos. Aunque el visón americano se haya convertido en una de las causas del declive del visón europeo, la responsabilidad moral no es del visón americano, sino de la industria peletera. Por tanto, no deberíamos decir "el visón americano causa la extinción del visón europeo" sino "la peletería causa la extinción del visón europeo".

Lo mismo sucede con las medidas prácticas que se toman para proteger al visón europeo. Se defiende con contundencia la necesidad de eliminar al visón americano, pero en cambio no se ha tomado la decisión de prohibir las granjas de peletería en España, que son las verdaderas culpables de esta catástrofe. Así, mientras matamos visones americanos con dinero público, las granjas de peletería continúan explotando estos animales e incrementando sus ganancias, y de ellas se pueden seguir escapando visones americanos. Si realmente no hay otro remedio que matar visones americanos, porque necesitamos esta medida extrema para evitar la extinción del visón europeo, entonces deberíamos también prohibir la industria peletera en España. Es decir, no es justo castigar con la muerte

24. Rejón, R. "La fuga de visones en las granjas peleteras obliga a gastar 16 millones de dinero público", Eldiario.es, 7/5/2016:

https://www.eldiario.es/sociedad/visones-peleteras-obligan-millones-publico_o_ 511999480.html 
a animales que no tienen responsabilidad moral alguna, y al mismo tiempo mantener en marcha el negocio moralmente responsable de esta situación. La única medida coherente con el exterminio del visón americano sería la prohibición de las granjas peleteras en España. Si el gobierno no toma esa decisión, está actuando de manera terriblemente hipócrita e irresponsable.

No debemos olvidar que los visones americanos son brutalmente maltratados en las granjas. ${ }^{25}$ Para un animal semiacuático que en la naturaleza vive en un territorio de varios kilómetros de río, estar encerrado toda su vida en una jaula diminuta en la que apenas puede moverse es una crueldad injustificable, como lo es también el hacinamiento. En esas condiciones, es imposible que puedan realizar sus conductas naturales y desarrollar sus capacidades cognitivas y emocionales de manera sana. Y sin embargo, cuando alguno consigue escapar de su encierro y puede vivir libre, se lo captura y mata porque su presencia amenaza a otras especies. No les damos ninguna opción, no les dejamos ninguna salida.

Aunque entiendo la urgencia de evitar que compitan con el visón europeo, y por tanto la necesidad de retirarlos de sus territorios, me pregunto si existiría alguna alternativa a su exterminio, si se ha contemplado la posibilidad de devolverlos a su hábitat. Supongo que tal medida resulta inasumible para las instituciones implicadas por su complejidad y su alto coste económico, dada la enorme cantidad de visones americanos que se han expandido por buena parte de Europa. Pero si no somos capaces de dar una solución ética a este problema que evite matar al visón americano, entonces matarlo no deja de ser un fracaso, y este fracaso ilustra una cuestión importante de la que deberíamos tomar conciencia: cuando los humanos explotamos a los otros animales y la naturaleza, tendemos a generar injusticias tan enormemente complejas, que una vez nos proponemos resolverlas, a menudo no encontramos una reparación que sea justa para todos los seres afectados. Es decir, creamos problemas tan envenenados que luego no sabemos darles una solución digna y razonable. La catástrofe ecológica que estamos provocando se caracteriza precisamente por esa capacidad humana para generar problemas que luego somos incapaces de resolver, lo que se observa con la pérdida de biodiversidad, con la cantidad de plásticos que están inundando los mares o con el caos

25. Igualdad Animal entrevista a un ex trabajador de una granja de visones, 27/7/2013: https://www.youtube.com/watch?v=XsCZxa79p-4

Documental de la televisión suiza SRF: “De la jaula al abrigo: la vida de los visones”, 13/2/2015: https://www.youtube.com/watch?v=tFaDAQIGN9s 
climático producido por las emisiones de gases de efecto invernadero. La suma de todos los problemas que estamos creando amenaza con generar una tormenta perfecta que ya no estará en nuestras manos resolver.

Volviendo al caso que nos ocupa, las víctimas son tanto el visón europeo como el americano, como el resto de especies afectadas. Son víctimas tanto a nivel individual como a nivel de especie. Y el único culpable de este desastre somos nosotros, los humanos, y deberíamos extraer una lección importante: la industria peletera causa tal daño que resulta injustificable. Causa daños tanto a las especies como a los individuos, y es enormemente dañina tanto si se basa en la caza de individuos salvajes como si cría en cautividad a los ejemplares que explota. Los individuos salvajes cazados pierden sus vidas y tienen muertes horribles, y los animales criados en cautividad sufren vidas miserables y muertes crueles. La caza por su piel causó el declive del visón europeo, y la cría en cautividad del visón americano acelera este declive. Si seguimos exterminando visones americanos sin prohibir las granjas peleteras, estamos atrapados en una cruel hipocresía, y en un círculo vicioso que sigue poniendo en peligro al visón europeo.

De hecho, diversos grupos animalistas y ecologistas han intentado reiteradamente en las últimas décadas prohibir o frenar la instalación de granjas de visón americano en España, pero sin éxito. Al contrario, así informa la periodista Mónica Nieto en el artículo "La producción de visón crece en Galicia con la apuesta de inversores extranjeros", publicado en El Progreso en fecha 24/12/2018: "La cría de visones para la venta de sus pieles en el mercado internacional prosigue su crecimiento en Galicia convertida en imán para inversores extranjeros que ven un filón en este negocio ante la fuerte demanda de materia prima para la industria peletera. Con clientes asegurados y unos precios que acompañan, la comunidad suma hoy 34 granjas en activo, seis más de las que operaban hace un lustro, y sigue copando prácticamente el $80 \%$ de las explotaciones de España. Una prueba de que la actividad va a más y gana adeptos son las tres nuevas instalaciones en ejecución y la veintena de explotaciones que se proyectan para un período de entre dos y cinco años. Estos datos los aporta la Asociación Gallega de Criadores de Visón (Agavi), que da cuenta del enorme interés que el sector despierta entre el capital foráneo, más concretamente europeo, impulsor de la mayor parte de granjas puestas en marcha en los últimos años. Con sus inversiones han contribuido a elevar una producción que, a nivel nacional, alcanzó las 750.000 pieles de media al año en las campañas de 2015 a 2017, en torno a un 15\% más en siete años. La mayoría se comercializa a través de casas de subastas internacionales 
especializadas en la materia, sobre todo las situadas en las capitales de Finlandia y Dinamarca, mientras un volumen "marginal" se vende a otra que opera en Canadá o a clientes directos."26

Galicia tiene ya una larga tradición en granjas de visón americano. "La primera granja de visón americano se instaló en Pontevedra en 1959, y entre 1980 y 1990 las plantas proliferaron hasta alcanzarse las 214. Las que sobrevivieron después crecieron y se "modernizaron"." ${ }^{27}$ Ahora, esas granjas vuelven a aumentar. El auge de la producción en Galicia se debe a que, en toda Europa, cada vez más países están prohibiendo las granjas de visón. "Austria y Gran Bretaña tienen prohibido las granjas peleteras desde hace más de una década. Pero otros países se han ido incorporando a la erradicación legal: Croacia, Bosnia-Herzegovina o Eslovenia han ido completando sus periodos transitorios para que las prohibiciones sean efectivas. Incluso Países Bajos, que era el segundo productor mundial, cerrará sus explotaciones en 2024. A esta tendencia se han unido recientemente Macedonia o la región belga de Valonia. Cuatro estados federales de Alemania tampoco permiten estas explotaciones." ${ }^{28}$

El negocio busca otros países donde instalarse, y Galicia se ofrece como una buena opción por su clima y porque la legislación es laxa. Que la producción de visón americano aumente en España, cuando ya somos tan conscientes del daño que causa, y cuando es necesario invertir tantos medios económicos y humanos para salvar al visón europeo, es una clara muestra de irracionalidad. "Solo en proyectos Life cofinanciados por la Unión Europea, los esfuerzos para revivir al visón europeo y controlar al americano se han llevado 8,6 millones de euros. Además, en Navarra, que alberga el 70\% de toda la población de visón autóctono en el suroeste del continente y todavía libre de colonias estables del invasor, se han invertido otros ocho millones de proyectos Life comunitarios para preservar ese santuario." ${ }^{29}$

De hecho, la peletería vive en una tensión creciente. Por un lado, el negocio crece, pero por otro, la presión de una parte de la sociedad contra esta

26. https://www.elprogreso.es/articulo/economia/produccion-vison-crece-galiciaapuesta-inversores-extranjeros/201811051247181342474.html

27. Pontevedra, S. R. "Firmas foráneas se refugian en Galicia para criar visón tras el veto europeo”, El Pais, 3/3/2013: https://elpais.com/ccaa/2014/02/28/galicia/1393605510_241756.html

28. Rejón, R. "La fuga de visones en las granjas peleteras obliga a gastar 16 millones de dinero público”, op. cit.

29. Rejón, R. "La fuga de visones en las granjas peleteras obliga a gastar 16 millones de dinero público”, op. cit. 
industria lleva a algunos países a tomar medidas contra las granjas de peletería, al tiempo que diversas marcas de moda han dejado de usar piel. La periodista Esther Sánchez resumía recientemente esa tensión. Por un lado: "Son miles los compradores que tiran del carro de una industria que mueve al año 30.000 millones de dólares (25.700 millones de euros), más del doble que hace 10 años. China copa el $70 \%$ de la producción mundial, seguida por Corea, Rusia, Estados Unidos y Europa, indica la Spanish Fur Association (SFA). [...] El viejo continente desempeña un papel fundamental en la cría de animales: sus casi 5.000 granjas producen el $52 \%$ de la materia prima mundial con 42 millones de pieles anuales. La de visón es la más popular, como demuestran los 39 millones de ejemplares que se criaron en las explotaciones europeas, según los últimos datos de SFA de 2016. Le sigue la de zorro, con 2,6 millones y, a mucha distancia, la chinchilla, con 210.000 ejemplares y la marmota con 160.000. España cuenta con 54 granjas peleteras (el $80 \%$ en Galicia) donde solo se crían visones: 750.000 en 2016." ${ }^{30}$

Sin embargo, al mismo tiempo, continúa Sánchez: "Algunos gobiernos, empujados por el debate ético y la presión social, ponen coto a las granjas de cría, prohibiéndolas o endureciendo de tal manera los requisitos para su funcionamiento, que aboca a las explotaciones a su desaparición debido al incremento de los costes. Alemania, por ejemplo, exige desde 2009 más espacio, agua para que los visones puedan nadar y un área que permita a zorros y marmotas escarbar. [...] La India cerró sus fronteras en 2017 a las importaciones de visón, zorro y chinchilla y Nueva Zelanda, al visón. [...] Diseñadores como Calvin Klein, Stella MacCartney, Ralph Lauren, Hugo Boss, Gucci, Armani o el español Adolfo Domínguez han desterrado el uso de pieles.” Asimismo, en 2018, la Semana de la Moda de Londres ya no incluyó prendas de piel. El Consejo de la Moda Británico, organizador del evento, explicó que la decisión responde al cambio de valores que está teniendo lugar en la sociedad. ${ }^{31}$

Cuando, en esta situación de tensión y debate creciente, los productores de visón tratan de defenderse, sus palabras están cargadas de cinismo. La Asociación Gallega de Criadores de Visón (AGAVI) incluye en su web un apartado llamado "Ecologismo", en el que leemos: “350.000 años nos avalan.

30. SÁnCHEZ, E. “Cerco a la cría de visones y zorros para peletería”, El País, 28/09/2018: https://elpais.com/sociedad/2018/09/23/actualidad/1537704812_127873.html.

31. Postico, D., "La pasarela de Londres se convierte en la primera en desfilar sin pieles de animales”, Cadena Ser, 9/9/2018: https://cadenaser.com/ser/2018/09/07/internacional/1536331003_541315.html 
Eudald Carbonell codirector de Atapuerca manifiesta que "En Atapuerca hay evidencia de curtido de pieles hace 350.000 años, con los Homo heildebergensis"." ${ }^{32} \mathrm{Al}$ realizar esta afirmación, dicha asociación parece desconocer dos ideas fundamentales para la ética. La primera es la siguiente: que una actividad se haya realizado durante miles de años no dice nada acerca de su legitimidad moral, ni siquiera de su conveniencia práctica. Que un error se repita tozudamente durante siglos no lo convierte en un acierto, solo indica que a veces los humanos aprendemos con demasiada lentitud. Y la segunda idea es que existe una diferencia abismal entre el modo en que nuestros antepasados cazadores-recolectores usaban pieles de animales dentro de una economía de subsistencia y la producción peletera en el marco de una sociedad industrial capitalista y globalizada. El número de animales matados en un caso y otro es simplemente incomparable, y también lo es el uso de las pieles. Para los cazadores-recolectores, las pieles de animales no eran productos de lujo que alimentaban negocios internacionales. ${ }^{33}$ La web todavía tiene la desfachatez de añadir: "La Federación Internacional de Comercio de la Piel (IFTF) promueve estrictos códigos de prácticas y estableció las normas aceptadas para el bienestar animal. El comercio de pieles no trabaja con especies en peligro de extinción.”

\section{Estética y PIELES AJENAS}

La causa última del declive del visón europeo es el deseo de algunas personas de vestir pieles de animales y el negocio multimillonario que se alimenta de satisfacerlo. El problema, así pues, se origina en los gustos estéticos de algunas personas, y se recrudece en una sociedad capitalista neoliberal que tiende a mercantilizar todo cuanto existe y a promover un consumismo desaforado.

La capacidad para apreciar estéticamente elementos naturales, así como para crear y apreciar elementos artificiales, ya sean obras de arte u objetos artesanales, es un rasgo fundamental del ser humano. La mayoría de nosotros nos sentimos mejor cuando estamos rodeados de entornos y objetos que nos proporcionan experiencias estéticas positivas, y al mismo tiempo nos agrada

32. http://agavi.es/ecologismo

33. Véase, por ejemplo, Lopez, B., Arctic Dreams, New York, Charles Scribner's Sons 1986. Traducción: Sueños árticos, Madrid, Capitán Swing 2017, traducción de Bofill, $\mathrm{M}$. 
tener una apariencia que consideramos bella, elegante, atractiva o sugerente. ${ }^{34}$ Nuestra relación con la naturaleza está muy mediada por nuestro anhelo de belleza natural..$^{35}$ Por todo ello, la dimensión estética de nuestras vidas es importante y merece atención filosófica. Y sin embargo, el problema es que nuestros gustos estéticos pueden llegar a estar enormemente influidos por la cultura en la que vivimos, y nuestra actual civilización fomenta una estética superficial y distorsionada, construida sobre el antropocentrismo, el clasismo y el patriarcado.

En una cultura que reduce los animales a meros ornamentos, que valora a las personas según su clase social, y juzga severamente a las mujeres por su apariencia, algunas consumidoras llegan a ver un abrigo de visón como una forma de exhibir una posición social elevada. El abrigo de piel presta una función estética que incluye una apariencia glamourosa y un significado ligado al poder económico, y más allá de eso, las compradoras no quieren saber de dónde procede ese objeto ni cómo ha sido fabricado. Por supuesto, al negocio de la peletería le conviene que sus compradores no indaguen demasiado en el proceso de elaboración, no vaya a ser que acaben descubriendo verdades incómodas. Por ello, la publicidad se encarga de tranquilizar a los clientes usando dos conceptos mágicos: cría en cautividad y bienestar. Se supone que si los animales fueron criados expresamente para ser matados y si fueron tratados según la legislación de bienestar animal, ya no hay nada doloroso ni injusto en el proceso y el cliente puede adquirir las pieles sin inquietud. Son los mismos conceptos mágicos que emplean muchas otras formas de explotación de animales, desde la producción de carne o huevos hasta los parques zoológicos.

En "Las otras víctimas de la moda" afirma Lucile Desblache: "El reemplazo del consumo de animales salvajes por animales de criadero o de clonaje en la alimentación y la moda (en particular en la peletería) es presentado y asumido como una solución aceptable por un público a menudo éticamente bien intencionado. Sin embargo, además de los sufrimientos que implica para los animales, plantea problemas cada vez más insolubles por la contaminación que genera, el control de enfermedades que implica y el aprovisionamiento de animales que exige. Moda, ropa, perfumería: los fabricantes y

34. Davies, S. J., “Analyzing Human Adornment”, The American Society for Aesthetics Newsletter, vol. 38, num. 2, (2018), pp. 1-4. Davies, S. J., The Artful Species. Aesthetics, Art, and Evolution, Oxford, Oxford University Press 2012.

35. Carlson, A. y Lintott, S. (eds.), Nature, Aesthetics, and Environmentalism. From Beauty to Duty, New York, Columbia University Press 2008. 
revendedores han tomado la costumbre de considerar a los animales como materias primas fácil y gratuitamente utilizables, como productos desechables, productos que se matan, transforman y venden. La idea según la cual la cría permite preservar la biodiversidad perpetúa así la peligrosa noción de que los seres humanos pueden construir y otorgarse a sí mismos un ser vivo controlado en paralelo al universo salvaje existente, y que, en ese vivero, todo está permitido." 36 Según la autora, nuestra sociedad fomenta un "consumo cuyo proceso implica la transformación de seres vivos en objetos desechables que contribuyen a halagar nuestro cuerpo o nuestro ego, a aumentar nuestro atractivo." ${ }^{37}$ Y propone en cambio pensar un sistema de la moda en que "los animales no fueran reducidos a objetos de lujo, a instrumentos masacrados y brutalmente apropiados. ${ }^{" 38}$

La filósofa Yuriko Saito, profesora en la Rhode Island School of Design, lleva años reflexionando acerca de las interrelaciones entre estética y ética a la hora de diseñar y adquirir productos en nuestra actual sociedad de consumo, ${ }^{39} \mathrm{y}$ denuncia: "There is a growing recognition that our aesthetic taste, preference, and judgment have far-reaching environmental consequences. More often than not, aesthetics seems to work against environmentally sound attitudes and practices." ${ }^{40}$ Como explica Saito, en las últimas décadas este problema se ha ido agravando con la fast fashion. En el actual sistema de la moda, los objetos quedan obsoletos cada vez más pronto. Esa obsolescencia no siempre tiene que ver con su utilidad, pues mucha de la ropa y otros objetos que compramos pueden tener una duración considerable, y los nuevos diseños no aportan mejor calidad. La obsolescencia se debe, simplemente, a que las prendas dejan de ser actuales según los criterios estéticos imperantes. Esto implica que algunas prendas de piel que han costado la vida a decenas de animales, dejan de ser atractivas de una temporada para otra, lo que exige volver a comprar prendas de piel. Lo mismo sucede con otros productos cuya elaboración es muy dañina para la naturaleza o cuya producción se traslada a países en vías de desarrollo donde los trabajadores sufren

36. Desblache, L., "Las otras víctimas de la moda”, en Puleo, A. H. (ed.), Ecología y género en diálogo interdisciplinar, Madrid, Plaza y Valdés 2015, traducción del francés de Puleo, A. H., p. 58.

37. Desblache, L., "Las otras víctimas de la moda”, op. cit., p 61.

38. Desblache, L., "Las otras víctimas de la moda”, op. cit., p. 62.

39. Saito, Y., Everyday Aesthetics, New York, Oxford University Press 2007.

40. Saito, Y., "Consumer Aesthetics and Environmental Ethics: Problems and Possibilities", The Journal of Aesthetics and Art Criticism, vol. 76, num. 4, (2018), p. 429. 
jornadas interminables a cambio de salarios de miseria. Productos cuya confección ha costado sufrimiento y daños medioambientales se compran para una temporada y se descartan rápidamente porque los consumidores están ansiosos por seguir el ritmo que dicta la moda.

Para hacer frente a este problema, Saito reivindica una estética cognitiva. Aunque la apreciación estética se centra en la apariencia de los objetos tal como se nos presentan a los sentidos, cada vez más filósofas y filósofos creen que una estética seria y profunda debe incluir el conocimiento y la reflexión crítica sobre los objetos apreciados. En este sentido, Saito se pregunta: “can we maintain the same aesthetic judgment of an object's appeal once its environmental cost becomes evident? [...] The answer, I submit, is no." ${ }^{\prime 1}$ Por esa razón, Saito propone desarrollar una nueva estética de los productos de consumo que nos aleje de aquellos que resultan dañinos para el medio ambiente o en cuya producción se violan derechos humanos, y nos acerque a productos respetuosos y sostenibles. Y una de las ideas centrales de esa propuesta es que apreciar un objeto no debe implicar tan solo contemplar su apariencia, sino también conocer su historia.

Demasiado a menudo, los consumidores adquieren objetos guiándose tan solo por su aspecto externo, y sin ninguna información acerca de cómo fueron producidos. "This problem of disconnect is what inspired the local food movement. The most common way of obtaining food from agribusiness, at least in the United States, alienates us from the production of food. The local food movement instead connects us closer to the farmers and farms that supplied the food, which tends to make us care, cherish, and value what we are cooking and eating. [...] We feel more connected to the food and such a feeling is bound to elevate its aesthetic profile in our experience. In contrast, people often become vegetarian not only for ethical reasons but also on aesthetic grounds after coming to know various harms done to the animals and environment: they can no longer enjoy the taste of meat." ${ }^{42} \mathrm{La}$ misma idea podría aplicarse al uso de la piel de animales para confeccionar prendas de vestir. Cuando una persona ve un abrigo de visón, pero sabe que ha sido elaborado con maltrato animal, y además comprende que las granjas de visón

41. SAito, Y. "Consumer Aesthetics and Environmental Ethics: Problems and Possibilities”, op. cit., p. 431. Véase un planteamiento similar en Maskit, J., "The Aesthetics of Elsewhere: An Environmentalist Everyday Aesthetics", Aesthetic Pathways, vol. 1, num. 2, (2011), pp. 92-107.

42. Saito, Y., "Consumer Aesthetics and Environmental Ethics: Problems and Possibilities”, op. cit., p. 434. 
americano son una de las causas del declive del visón europeo y provocan daños a otras especies y al entorno en su conjunto, es imposible apreciar ese abrigo como un objeto bello y atractivo. Al contrario, su historia lo revela como un objeto horrible.

La idea de recuperar la historia del objeto es a la que apelan también algunas campañas contra la peletería organizadas desde el movimiento animalista, y que consisten en diseñar imágenes que contraponen el abrigo de visón con los cuerpos maltratados de los animales. En los cadáveres de visones despellejados y amontonados unos sobre otros como si solo fueran desechos, apreciamos una fealdad que es la expresión sensible del dolor, y esa fealdad hace imposible seguir apreciando belleza en los abrigos de piel.

En lo que se refiere al uso de animales para producir prendas de piel y otros objetos similares, propongo teorizarlo con el concepto de instrumentalización estética. En la ética filosófica son ya muchos los estudios que denuncian la reducción de los animales a meros instrumentos, tanto en la concepción que tenemos de ellos como en el trato que les conferimos. ${ }^{43}$ En nuestra civilización, los animales no son valorados por los diversos elementos que conforman sus identidades siempre complejas, sino que son reducidos a aquellos elementos por los cuales los explotamos. En nuestra civilización se les trata y mata como si las vacas tan solo fueran grifos de leche, las gallinas fuentes de huevos, las ovejas fábricas de lana, los salmones productores de sushi o los caballos vehículos de transporte. Los animales son reducidos a un elemento de su identidad y concebidos como meras herramientas a nuestra disposición. La instrumentalización estética consiste en reducir los animales a ornamentos, como si tan solo existieran para proporcionar placer a nuestros sentidos, y un ejemplo paradigmático es la peletería.

Para la industria peletera, lo único que tiene valor de un animal es su piel, que será convertida en adorno para un cuerpo humano. Paradójicamente,

43. Por ofrecer tan solo algunos ejemplos recientes:

Donaldson, S. \& Kymlicka, W., Zoopolis. A Political Theory of Animal Rights, New York, Oxford University Press 2011. Traducción: Zoópolis. Una revolución animalista, Madrid, Errata Naturae 2018, traducción de Moreno Parrado, S.

Wolf, U., Ethik der Mensch-Tier-Beziebung, Frankfurt am Main, Vittorio Klostermann 2012. Traducción: Ética de la relación entre humanos y animales, Madrid, Plaza y Valdés 2014, traducción de Gabás Pallás, R.

Puleo, A. H., Ecofeminismo para otro mundo posible, Madrid, Ediciones Cátedra 2011.

Velasco Sesma, A., La ética animal. ¿Una cuestión feminista?, Madrid, Ediciones Cátedra 2017.

Horta, O., Un paso adelante en defensa de los animales, Madrid, Plaza y Valdés 2017. 
si el animal puede ser convertido en un adorno es porque nos parece bello. Toda la industria peletera se sostiene en que muchas personas aprecian belleza en visones, zorros o chinchillas. Pero la peletería entiende esa belleza de tal modo que la aprecia desconectada del propio animal. Se produce una disociación radical: por un lado, ese aspecto externo del animal que nos resulta atractivo, como el color y las sensaciones táctiles que apreciamos en la piel del visón, calidez y suavidad; y por otro lado, la identidad del animal, su capacidad para sentir placer y dolor, sus capacidades cognitivas, emocionales y comunicativas, su conducta, su forma de vivir, su relación con sus congéneres y con otros seres vivos, su relación con los ecosistemas que habita, la personalidad y la historia particular de cada individuo.

El comprador de un abrigo de visón aprecia al visón como bello, pero en realidad, el visón no le importa en absoluto; ni le importan los individuos particulares matados para elaborar el abrigo, ni tampoco el futuro de las especies afectadas. Se trata, pues, de una estética superficial y distorsionada, que tan solo percibe de ese animal su pelaje, y lo concibe como algo que le puede ser sustraído y transformado en una mercancía, un objeto de consumo. En realidad, una apreciación estética de los animales seria y profunda no puede disociar el aspecto externo de un animal respecto del resto de elementos que conforman su identidad. Apreciar una especie animal implica apreciar su forma de vida en su hábitat, y apreciar un individuo de esa especie incluye atender a su personalidad individual y a su historia particular. Cuando se aprecia a los animales de una forma seria y profunda, se entiende que los animales no son solo cuerpos, sino sobre todo formas de vivir, relaciones con otros seres y con el entorno, historias personales.

Para quien practique esa apreciación estética seria y profunda, un abrigo de piel de visón no es un objeto bello y atractivo, no es un símbolo de glamour y elegancia, porque se ha elaborado robando la belleza de los animales explotados, y robando la belleza de las especies y ecosistemas dañados por la peletería. En la producción de un solo abrigo de visón apreciamos tanta fealdad, esa fealdad que es la expresión del sufrimiento de los animales, que por muy bella que fuera la piel del visón, el abrigo la ha convertido en un objeto monstruoso.

\section{El PRoblema de FOndo: Un ANHELo DE Belleza NATURAL QUE LA DESTRUYE}

Este caso concreto que hemos examinado permite ilustrar uno de los problemas fundamentales de nuestra civilización: la mayoría de la gente aprecia 
la belleza natural, pero demasiado a menudo quiere disfrutarla de un modo que en realidad contribuye a destruirla. Los ejemplos son innumerables: uno quiere pasear por la montaña, pero para ello toma el coche privado; uno quiere visitar playas paradisíacas, pero llega hasta ellas en avión; uno quiere adornar su casa con motivos africanos, pero compra figuritas de marfil y pieles de guepardo; uno quiere tener animales de compañía, pero elige mapaches o cotorras argentinas...

Los seres humanos deseamos disfrutar de la belleza natural, pero nuestra civilización, cada vez más dominada por un neoliberalismo enloquecido, encauza ese deseo para transformarnos en consumidores compulsivos de objetos que parecen prometer esa belleza natural, pero que en realidad contribuyen a destruirla. Reducimos la naturaleza a escenarios, decorados y ornamentos que están ahí para que los disfrutemos sin pensar en las consecuencias de nuestros actos; convertimos la naturaleza entera en mercancías que usamos sin remordimientos porque hemos pagado por ellas, y la explotamos sin mesura alguna. Nuestra manera de relacionarnos con la naturaleza, guiados por una estética superficial y distorsionada, por deseos egoístas de consumir sin cesar, provoca dolor a innumerables individuos animales, y al mismo tiempo extingue especies, desequilibra ecosistemas, y está comenzando a poner en riesgo la biosfera en su conjunto. La alianza perversa entre una estética superficial que reduce la naturaleza a meros ornamentos, un capitalismo neoliberal que mercantiliza todo cuanto existe y un consumismo desaforado, están causando una catástrofe ecológica que comienza a amenazar nuestra propia civilización.

Es por esta razón que, si deseamos desarrollar una ética ecológica y una ética animal capaces de hacernos reconsiderar nuestra forma de vida, necesitamos tener en cuenta la estética. ${ }^{44}$ Hemos de entender que muchos comportamientos dañinos para la naturaleza están guiados por esa estética banal que nuestra sociedad promueve, y a la vez mostrar que el verdadero disfrute de la belleza natural no se logra comprando mercancías producidas de manera injusta, sino de formas mucho más sencillas y sostenibles. En realidad, esa alianza entre capitalismo neoliberal, consumismo enloquecido y estética superficial que resulta tan dañina para la naturaleza, también lo es para nosotros, pues no nos proporciona las experiencias de encuentro con la naturaleza que promete, y nos deja tan encerrados en placeres banales y

44. Eso es lo que intento explicar en: Tafalla, M., Ecoanimal. Una estética plurisensorial, ecologista y animalista, Plaza y Valdés, 2019. 
triviales, que llegamos a olvidar lo profundas e intensas que pueden ser las experiencias estéticas de la naturaleza.

Disfrutar de la belleza natural es algo mucho más sencillo, que nada tiene que ver con dominar la naturaleza, explotarla, mercantilizarla, poseerla y consumirla. La experiencia estética de contemplar a un visón nadando libremente en un río es mucho más placentera y profunda que lucir un abrigo confeccionado con su piel, porque implica contemplar un sujeto viviendo su vida y tejiendo su historia personal, en vez de reducirlo a un mero objeto, e implica asimismo reconectar con otras formas de vida, comprenderlas, y reencontrar nuestro lugar en la comunidad multiespecie que es la biosfera. Es porque hemos olvidado placeres profundos y sencillos como salir a caminar cerca de nuestra casa y contemplar la fauna y la flora local, por lo que esta civilización puede tomarnos el pelo con falsas promesas de belleza natural que nunca es capaz de satisfacer. ${ }^{45} \mathrm{El}$ mejor antídoto contra el consumismo desaforado de productos dañinos para la naturaleza, es aprender a gozar de la belleza natural de una manera seria, profunda y respetuosa. A menudo, es tan sencillo como colgarse unos prismáticos, coger una guía de naturaleza, y salir a observar el entorno que nos rodea. Incluso un parque urbano puede estar lleno de maravillas si sabemos reconocerlas. Y cuanto menos intentemos dominar, y más nos abramos a contemplar con respeto y admiración, más intensas serán las experiencias estéticas. Si aprendemos a disfrutar de la belleza natural, dejarán de resultarnos tentadoras esas redes del consumismo que intentan atraparnos con placeres banales. Contemplar la belleza natural nos revelará que existe una conexión muy íntima entre la libertad de la naturaleza y nuestra propia libertad.

45. Louv, R., Last Child in the Woods: Saving Our Children From Nature-Deficit Disorder, Chapel Hill, Algonquin Books of Chapel Hill 2005. Traducción: Los últimos niños en el bosque. Salvemos a nuestros hijos del trastorno por déficit de naturaleza, Madrid, Capitán Swing 2018, traducción de Valle, B. 
